CONF-920707--21

DE92 008736

Submitted for presentation at the 24th International Symposium on Combustion

The University of Sydney, Sydney, A ustralia, 5-10 July, 1992

\title{
INHIBITION OF MOIST CARBON MONOXIDE OXIDATION BY TRACE AMOUNTS OF HYDROCARBONS
}

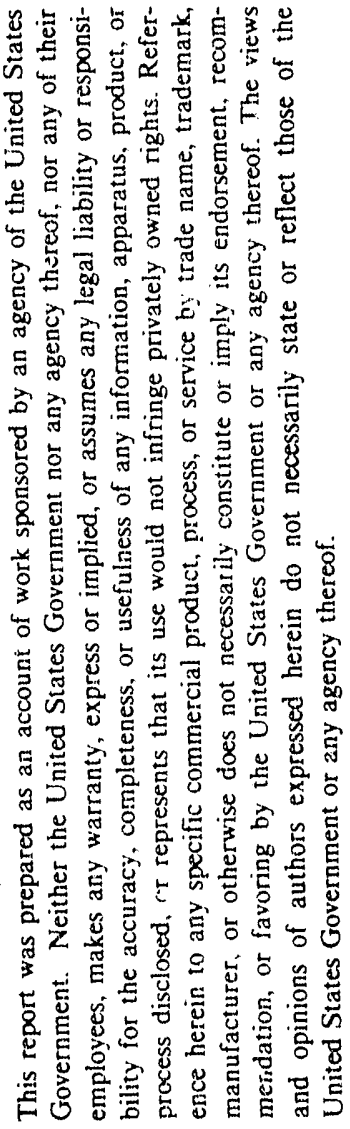

\author{
R.A. Yetter and F.L. Dryer \\ Department of Mechanical and Aerospace Engineering \\ Princeton University \\ Princeton, NJ 08544 \\ FGO2-86EN/3503 \\ Subject matter: \\ (8.0) Kinetics \\ (8.1) Elementary Rates \\ (8.2) Detailed Mechanisms
}

Corresponding Author:

R.A.Yetter

Department of Mechanical and Aerospace Engineering

Princeton University

Princeton, NJ 08544

Phone: (609) 258-2947, FAX: (609) 258-1939

Page Length:

Text ( 3380 words $)+2$ Tables ( 400 words $)+8$ Figures $(1600$ words $)=5380$ words 


\title{
INHIBITION OF MOIST CARBON MONOXIDE OXIDATION BY TRACE AMOUNTS OF HYDROCARBONS
}

\author{
R.A. Yetter and F.L. Dryer \\ Department of Mechanical and Aerospace Engineering \\ Princeton University \\ Princeton, NJ 08544
}

\begin{abstract}
The moist carbon monoxide oxidation reaction perturbed by small quantities of hydrocarbons is studied over the temperature range 1026-1140 $\mathrm{K}$ at $1 \mathrm{~atm}$ to yield information on the reactions of $O H, H$, and $O$ radicals with hydrocarbons $(R H)$ and on general mechanistic inhibition behavior. The inhibiting action of hydrocarbons below the second explosion limit of $\mathrm{CO} / \mathrm{H}_{2} \mathrm{O} / \mathrm{O}_{2}$ mixtures is used for obtaining rate parameters for $\mathrm{RH}+\mathrm{OH}$ in the case of methane and propene. Considering all the hydrocarbons studied, the general ranking of effectiveness as an inhibitor was found to follow the order: propene > propane $>$ methane $>$ ethane $>$ ethene $>$ acetylene. In fact, acetylene was observed to always promote the oxidation of moist $C O$, thus emphasizing the importance of $O$-atom radical attack rather than $\mathrm{OH}$ attack on acetylene. The kinetics of these mixtures are shown to complement mechanistic studies on $\mathrm{RH} / \mathrm{O}_{2}$ mixtures for the development and validation of hierarchical hydrocarbon oxidation reaction mechanisms.
\end{abstract}




\subsection{Introduction}

The study of trace amounts of hydrocarbons reacting in the presence of moist carbon monoxide oxidation is of interest for several reasons. As illustrated by the highlighted areas in Fig. 1, this chemistry is present in both premixed and non-premixed combustion. Because the oxidation of $C O$ typically accounts for a significant amount of the total heat release in these flames, the temperature profile is dependent on the rate of this reaction as well as the energy transport away from the region of this reaction. Clearly, an understanding of how the hydrocarbon interacts with carbon monoxide oxidation is relevant to pollutant emissions and to the extinction and ignition of flames. As a diagnostic tool, the moist carbon monoxide system can provide a convenient chemical method for generating large quantities of oxygen, hydrogen, and hydroxyl radicals with relative quantities varied by changing the initial conditions of the carbon monoxide system. Thus when a small quantity of a hydrocarbon is added, the elemental kinetics (in particular, the rate parameters and product channels) of the primary hydrocarbon interacting with the radical pool can be studied.

The present article reports experimental kinetics data on the interaction chemistry between the $\mathrm{CO} / \mathrm{H}_{2} \mathrm{O} / \mathrm{O}_{2}$ reaction and various hydrocarbons $(\mathrm{RH})$. in addition, a detailed analysis of moist $\mathrm{CO}$ oxidation perturbed by small quantities of methane is described from which a rate constant for the reaction $\mathrm{CH}_{4}+\mathrm{OH}$ is derived. Studies similar to the present one have been common to chemical kinetics research for many years. Baldwin and co-workers ${ }^{1}$ are probably the most renowned in applying such a technique. They used the $\mathrm{H}_{2} / \mathrm{O}_{2}$ reaction at temperatures around $500 \mathrm{C}$ and at pressures below the second explosion limit. The features of the inhibition on the second limit in $\mathrm{KCL}$ - coated vessels were studied with formaldehyde, ${ }^{2}$ ethane, ${ }^{3,4}$ propane, ${ }^{5}$ n- and i-butane, ${ }^{6}$ and other hydrocarbons, ${ }^{7-9}$ and the efficiency of inhibition was assessed by studying the amount of inhibitor required to half the second limit. In other studies, ${ }^{10-12}$ they measured the relative rates of $\mathrm{H}_{2}$ and additive disappearance, $\Delta[R H] / \Delta\left[H_{2}\right]$, when small amounts of hydrocarbons were added to slowly reacting mixtures of hydrogen and oxygen. The ensuing analyses led to the relative evaluation of a number of $\mathrm{H}$-atom abstraction reaction rate parameters. Other related works in clude those of Brabbs and Brokaw ${ }^{13}$ and Skinner. ${ }^{14}$ The present work differs from those mentioned above both in temperature range (1026-1140 K) and in the experimental/analysis technique.

\subsection{High Temperature Kinetics of $\mathrm{CO} / \mathrm{H}_{2} \mathrm{O} / \mathrm{O}_{2} / \mathrm{RH}$ Mixtures}

Detailed investigation of $\mathrm{CO} / \mathrm{H}_{2} \mathrm{O} / \mathrm{O}_{2}$ kinetics at 1 atmosphere pressure over the temperature range of $1026-1140 K^{15}$ has shown that the disappearance of carbon monoxide can be accounted for by a mechanism including the propagation reaction,

$$
\mathrm{CO}+\dot{\mathrm{OH}} \rightarrow \mathrm{CO}_{2}+\dot{\mathrm{H}}
$$

the two chain branching reactions,

$$
\dot{H}+\mathrm{O}_{2} \rightarrow \dot{O} H+\ddot{O}
$$




$$
\ddot{O}+\mathrm{H}_{2} \mathrm{O} \rightarrow \dot{O} \mathrm{H}+\dot{O} H
$$

and the three chain breaking reactions,

$$
\begin{gathered}
\dot{O H}+\ddot{O} \rightarrow \dot{H}+\mathrm{O}_{2} \\
\dot{O} \mathrm{H}+\dot{\mathrm{O} H} \rightarrow \ddot{O}+\mathrm{H}_{2} \mathrm{O} \\
\dot{H}+\mathrm{O}_{2}+\mathrm{M} \rightarrow \mathrm{HO}_{2}+\mathrm{M} .
\end{gathered}
$$

The numbers to the right of each reaction denote their listings as reported in Ref. 20.

At these conditions, $C O$ is oxidized essentially by reaction with hydroxyl radical. Consequently, the reactions of $\mathrm{CO}$ with $\mathrm{O}$-atoms and with $\mathrm{HO}_{2}$ radicals may be neglected without introducing significant error. However, the formation of $\mathrm{HO}_{2}$ as an intermediate must be included as it provides a sink for $H$-atoms. Its presence effectively decreases the $O, H$, and $\mathrm{OH}$ radical concentrations and hence, moderates the conversion of $\mathrm{CO}$ to $\mathrm{CO}_{2}$. Above approximately $1030 \mathrm{~K}$, reactions of $\mathrm{HO}_{2}$ with other intermediates are of secondary importance. ${ }^{16}$ During the induction period, the chain breaking reactions, 16 ind 20, are inactive; however, the reaction of $\mathrm{CO}$ with $O$-atoms cannot be neglected es. recially for fuel rich mixtures.

The inhibiting action of small quantities of hydrocarbons on the rate of conversion of $\mathrm{CO}$ to $\mathrm{CO}_{2}$ can te accounted for in general terms by adding to the above mechanism the abstraction reactions

$$
\begin{gathered}
R H+\dot{H} \rightarrow \dot{R}+H_{2} \\
R H+\dot{O} H \rightarrow \dot{R}+H_{2} O \\
R H+\ddot{O} \rightarrow \dot{R}+\dot{O} H
\end{gathered}
$$

By seeding with only small quantities of the hydrocarbon, the importance of secondary reactions,

$$
\begin{gathered}
\dot{R}+\mathrm{O}_{2} \rightarrow \mathrm{HO}_{2}+\text { olefin } \\
\dot{R}+M \rightarrow\left[\begin{array}{l}
\dot{H} \\
\dot{R}^{\prime}
\end{array}\right]+\text { olefin }+M
\end{gathered}
$$

the reactions

$$
\dot{R}^{\prime}+\left[\begin{array}{c}
\dot{O} \\
\dot{O} H \\
\mathrm{HO}_{2}
\end{array} \mid \rightarrow C O\right.
$$


which eventually lead to the formation of carbon monoxide, and the reactions,

$$
R+? \rightarrow R H+?
$$

which regenerate the primary hydrocarbon can be minimized and in many cases neglected. This simplified scheme assumes that $\mathrm{HO}_{2}$ radicals are again destroyed without continuing the chain. The validity of the simplified scheme described above depends on many factors, e.g., the hydrocarbon studied, the stability of the hydrocarbon radical, the environmental parameters, etc. Each hydrocarbon requires a separate and careful analysis of the possible reaction channels and secondary reactions.

The effects of the hydrocarbon-radical reactions on moist $\mathrm{CO}$ oxidation can be intuitively understood by comparison of their rates with the corresponding radical reactions of the $\mathrm{CO}$ system. Table 1 reports rates of $O H, H$, and $O$ radical attack on several hydrocarbons and on $\mathrm{CO}, \mathrm{O}_{2}$, and $\mathrm{H}_{2} \mathrm{O}$, respectively, at temperatures of 1000,1200 , and $2000 \mathrm{~K}$. For each of the radicals, the rate of reaction with the hydrocarbon is faster than with any of the reactants of the moist $\mathrm{CO}$ oxidation reaction. Consequently, the hydrocarbon acts to inhibit the oxidation of $\mathrm{CO}$ by replacing an active chain carrier with a less active one. Because the hydrogen abstraction reaction of $R H$ by $O$-atoms produces $O H$ radicals, its role in inhibiting the reaction is significantly less than thai of $\mathrm{H}$ or $\mathrm{OH}$ with $\mathrm{RH}$. Hence, anywhere (temporally ur spatially) that the ratios $\left[\mathrm{RH}_{H}\right] /[\mathrm{CO}]$ or $[\mathrm{RH}] /\left[\mathrm{O}_{2}\right]$ satisfy

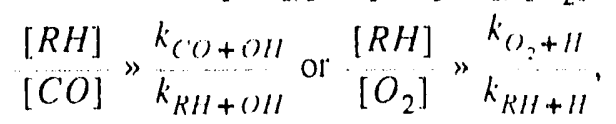

the oxidation of $C O$ is essentially nonexistent. When these ratios are

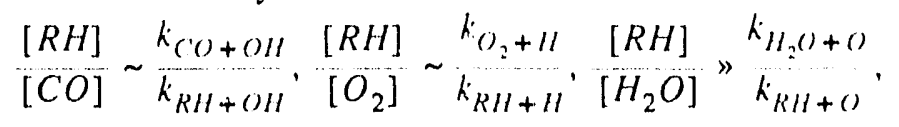

the oxidation rate is slowed relative to the unperturbed reaction, and when the concentration ratios are all considerably less than the rate constant ratios, the oxidation of $C O$ is not significantly affected.

These ratios also suggest the mixture composition of the $\mathrm{CO} / \mathrm{H}_{2} \mathrm{O} / \mathrm{O}_{2}$ system necessary to emphasize a particular radical reaction with the added hydrocarbon. For example, extremely lean mixtures with high water concentrations will emphasize the reaction between $\mathrm{RH}$ and $\mathrm{OH}$. Near stoichiometric mixtures with high $\mathrm{H}_{2} \mathrm{O}$ concentrations will emphasize the reactions $\mathrm{RH}+\mathrm{OH}$ and $\mathrm{RH}+\mathrm{H}$.

Two important differences exist iatween the $\mathrm{CO} / \mathrm{H}_{2} \mathrm{O} / \mathrm{O}_{2}$ system studied here and the $\mathrm{H}_{2} /$ $\mathrm{O}_{2}$ system studied by Baldwin and co-workers. First, the reaction of $\mathrm{OH}$ with $\mathrm{CO}$ is considerable slower than that of $\mathrm{OH}$ with $\mathrm{H}_{2}$ (Table I), and thus for a given reaction time, higher temperatures can be studied. Second, in the $C O$ system with water vapor as the source of hydrogen, $\mathrm{H}$-atoms are generated almost entirely by the reaction of $\mathrm{CO}$ with $\mathrm{OH}$, whereas in the $\mathrm{H}_{2}$ system, $\mathrm{H}$-atoms are formed both by reaction of $\mathrm{H}_{2}$ with $\mathrm{OH}$ and by reaction of $\mathrm{H}_{2}$ with $\mathrm{O}$-atoms. Thus, production of chain carriers among the two systems is controlled by different mechanisms resulting in different branching factors. 
In order to illustrate the kinetics described above, a set of modeling and sensitivity analysis calculations has been performed for the moist $C O$ oxidation reaction perturbed by a small quantity of methane. The kinetics of this system are compared with those of a system consisting only of the reactants methane and oxygen. The calculations were performed for a homogeneous, isothermal system using the computer codes CHEMKIN ${ }^{17}$ $\mathrm{AIM}^{18}$ and $\mathrm{LSODE}^{19}$ with a detailed reaction mechanism for methane oxidation, ${ }^{20}$ which included $C_{2}$ chemistry and was based on literature rate constants. Figure 2 reports the sensitivity of the methane concentration to variations in the rate constants of the mechanism $\left(\partial \ln \left[\mathrm{CH}_{4}\right] / \partial \ln k_{j}\right)$ as a function of percent methane consumed for a mixture of $1 \%$ $\mathrm{CH}_{4}$ and $20 \% \mathrm{O}_{2}$ reacting at $1150 \mathrm{~K}$ and $1 \mathrm{~atm}$ in nitrogen. Figure 3 shows the same gradients but for a mixture of $1 \% \mathrm{CO}, 3 \% \mathrm{H}_{2} \mathrm{O}, 20 \% \mathrm{O}_{2}$ and $500 \mathrm{ppm} \mathrm{CH}_{4}$ reacting at the same temperature and pressure. Part (a) of each figure presents the positive gradients and part (b), the negative gradients. Note also the scale change occurring at unity.

An obvious difference between the two systems is the subset of reactions with greatest importance (look particularly at the reactions with sensitivity gradients greater than unity). For the carbon monoxide reaction seeded with methane, the reactions of importance are those anticipated from the unperturbed reaction, and in addition, the reaction $\mathrm{CH}_{4}+\mathrm{OH}$. The influence of secondary reactions is minimized until approximately $80 \%$ of the initial methane is consumed. For the methane-oxygen system, the secondary reactions are important from the start of oxidation. Here, the fate of the methyl radical controls the formation of the radical pool, and therefore indirectly controls the oxidation of methane. Furthermore, as more of the methane is consumed, the number of secondary reactions having a controlling effect on the methane concentration increases continuously. Conseguently, for these two particular mixtures, the seeded reaction is actually less complex than the pure $\mathrm{RH} / \mathrm{O}_{2}$ reaction. Moreover, these results clearly demonstrate that selected reactions from the $\mathrm{RH}_{\mathrm{O}} \mathrm{O}_{2}$ systems may be isolated in combination with the important (and generally well studied) reactions of the $\mathrm{CO} / \mathrm{H}_{2} \mathrm{O} / \mathrm{O}_{2}$ system.

\subsection{Experimental}

Experiments were performed at atmospheric pressure using a flow reactor described in detail elsewhere. ${ }^{21,22}$ All procedures remained the same as those previously reported for the $\mathrm{CO} / \mathrm{H}_{2} \mathrm{O} / \mathrm{O}_{2}$ experiments ${ }^{23}$ except for the analysis of the extracted gas sample. In addition to the continuous monitors for $\mathrm{CO}, \mathrm{CO}_{2}$, and $\mathrm{O}_{2}$, the present experiments employed sample storage via a multi-position valve, which was capable of storing 15 discrete 12 -cc gas samples at 1.5 atmospheres. With the storage valve, the gas samples were analyzed using a Hewlett - Packard model 5880 gas chromatograph equipped with a methanation catalyst/ flame ionization detector and a thermal conductivity detector. The design and analysis of the multi-position valve (e.g., for sample leakage, sample to sample diffusion, repeatability, chemical contamination, etc.) have been described by Euchner, ${ }^{24}$ and the valve switching/column arrangement/temperature programing of the gas chromatograph (GC) by Proscia. ${ }^{25}$ Calibration procedures have been reported by Venkat. ${ }^{26}$ The tested gases were from Matheson: $\mathrm{CO}$ (99.9\% purity), $\mathrm{CH}_{4}(99.99 \%), \mathrm{C}_{2} \mathrm{H}_{2}$ (99.0\%), $\mathrm{C}_{2} \mathrm{H}_{4}(99.5 \%), \mathrm{C}_{2} \mathrm{H}_{6}$ $(99.0 \%), C_{3} H_{6}(99.0 \%)$, and $C_{3} H_{8}(99.0 \%)$. 
In the first series of experiments, the hydrocarbon concentration was continuously increased and the inhibiting effect on the $C O$ concentration profile was investigated at a specific reaction time. In a second series of experiments, the hydrocarbon level was maintained at very small concentrations and the $C O$ reactant bath conditions were varied. Here, the disappearance profiles of each reactant as a function of flow tube axial position were monitored. Specific results of the latter experiments are presented for methane.

\subsection{Results and Discussion}

\subsection{Inhibition Trends of Various Hydrocarbons}

The $[\mathrm{CO}]$ profiles for the uninhibited reaction of three different $\mathrm{CO} / \mathrm{H}_{2} \mathrm{O} / \mathrm{O}_{2}$ mixtures are shown in Fig. 4. Mixture $\mathscr{A}$ is a fuel lean system; mixture $B$ is a fuel rich system obtained by decreasing the initial $\mathrm{O}_{2}$ concentration of mixture $\mathscr{A}$; and mixture $C$ is similar to $\mathcal{A}$ with regards to equivalence ratio, but with a reduction in water vapor concentration. Modeling calculations predict the $\mathrm{H}$-atom concentration to increase and the $O$-atom concentration to decrease in going from mixture $A$ to $\mathcal{B}_{1}$ and the $O H$ concentration to decrease in going from mixture $A$ to $C$.

The results of the inhibiting action of several hydrocarbons are presented by observing their affect on the $\mathrm{CO}$ and $\mathrm{O}_{2}$ concentrations at a reaction time of $84 \mathrm{~ms}$. Figure 5 shows the inhibition results for mixture $\mathcal{A}$. Part (a) shows the $C O$ concentration at $84 \mathrm{~ms}$ vs. initial hydrocarbon concentration, and part (b), the $\mathrm{O}_{2}$ concentration. Figure 6 shows the $[C O$ ] for mixtures $\mathcal{B}$ and $\mathcal{C}$. Some qualitative observations from these results are:

- For each system, the ranking of effectiveness as an inhibitor of the $C O$ reaction is observed to follow the order: propene $>$ propane $>$ methane $>$ ethane $>$ ethylene $>$ acetylene.

- For a particular initial concentration of $\mathrm{C}_{3} \mathrm{H}_{8}, \mathrm{C}_{3} \mathrm{H}_{6}$, or $\mathrm{CH}_{4}$, the $\mathrm{CO}$ reaction is observed to be rapidly inhibited as can be seen by the sudden change from reacted to unreacted $\mathrm{CO}$ and $\mathrm{O}_{2}$ concentrations. In the case of the $\mathrm{C}_{2}$ - species, the slower inhibition eventually produces a $\mathrm{CO}$ concentration larger than the initial $\mathrm{CO}$ concentration indicating that some of the $C_{2}$ - species has been converted to $C^{\prime} O$.

- For fuel lean systems (mixtures $\mathcal{A}$ and $\mathcal{C}$ ), the addition of very small amounts of certain hydrocarbons can actually catalyze the $C O$ reaction, and in particular for acetylene, the extent of $\mathrm{CO}$ reaction increases with increasing $\mathrm{C}_{2} \mathrm{H}_{2}$ concentration until all of the excess oxygen is consumed, at which point the $\mathrm{CO}$ reaction is inhibited.

- Addition of hydrocarbons to overall fuel lean mixtures produces decreasing linear responses between the added $[\mathrm{RH}]$ and the reacted $\left[\mathrm{O}_{2}\right]$. Addition of $\mathrm{C}_{2}$ - hydrocarbons to the overall fuel rich mixture produces a linear relationship between the added $[R H]$ and the inhibited [CO].

- If the effectiveness of inhibition is defined as the concentration of $R H$ required to produce a $\mathrm{CO}$ concentration at a reaction time of $84 \mathrm{~ms}$ equal to $1 / 2\left([\mathrm{CO}]_{i}-[\mathrm{CO}]_{\text {uninhibited }}\right)$, then the relative effects of variation of $\mathrm{O}_{2}$ and $\mathrm{H}_{2} \mathrm{O}$ concentration can be reported. In 
particular, by decreasing the initial $\mathrm{O}_{2}$ concentration from 0.93 to $0.31 \%$, the inhibiting $\mathrm{RH}$ concentration decreased by $75 \%$ for the $\mathrm{C}_{3}$ - species, by $80 \%$ for $\mathrm{CH}_{4}$, by $88 \%$ for $\mathrm{C}_{2} \mathrm{H}_{6}$, and by $90 \%$ for $\mathrm{C}_{2} \mathrm{H}_{4}$. Furthermore, by decreasing the initial $\mathrm{H}_{2} \mathrm{O}$ concentration from 0.79 to $0.27 \%$, the inhibiting $R H$ concentrations for all hydrocarbons decreased hy $50 \%$.

The transition from the completely inhibited to the uninhibited $\mathrm{CO}$ reaction represents a change from a slow, steady reaction to a fast, branched chain reaction. The actual hydrocarbon concentration present when the transition occurs may and usually does differ from the initial hydrocarbon concentration. Consequently, the ranking of inhibitors based upon initial hydrocarbon concentration as presented above may be misleading. However, several important implications may still be deduced from these observations. First, they demonstrate that measurable differences in rates of reaction do occur for different hydrocarbons, and more importantly, for different mixtures. This latter fact is essential to uncouple information regarding $O, H$, and $O H$ reactions. Sensitivity to mixture composition is demonstrated in the last observation above. For example. Fig. 2 shows that the rate of the uninhibited reaction changes by approximately $50 \%$ when the water vapor concentration was reduced from 0.79 to $0.27 \%$. The resulting decrease in the critical hydrocarbon concentrations was also $50 \%$, thus indicating the importance of the reaction between the hydrocarbon and $\mathrm{OH}$. In going from the fuel-lean to the fuel-rich mixture, the $\mathrm{OH}$ concentration remains nearly constant, which is evident from the nearly identical $\mathrm{CO}$ consumption rates of the uninhibited reaction (Fig. 2), while the $O$-atom concentration decreases and the $H$-atom concentration increases. From the discussion of the last section, the increase in $\mathrm{H}$-atom concentration is expected to have the greatest effect on the trends of the critical hydrocarbon level. Hence, the ratio of $k_{R H+H} / k_{R H}+O H$ should vary inversely to the change in critical $R H$ level. Indeed for all paraffins, this ratio increases in the order of $\mathrm{C}_{3} \mathrm{H}_{8}<\mathrm{CH}_{4}<\mathrm{C}_{2} \mathrm{H}_{6}$ (see Table I), which is consistent with the observed decrease in critical $\mathrm{RH}$ concentration. This trend does not hold for $\mathrm{C}_{2} \mathrm{H}_{4}$, thus emphasizing the importance of $\mathrm{O}$-atom attack and its production of $\mathrm{H}$-atoms. The second observation above is also consistent with the importance of $O$-atom reactions for $C_{2}$-species.

In combustion systems, these results suggest that of the hydrocarbons studied here, the only one that can survive with appreciable concentrations into the post-flame region of a laminar premixed flame or into the fuel-lean region of a laminar diffusion flame is acetylene. The results also show that although oxygen leakage into the fuel-rich region of a diffusion flame is possible, hydrocarbon leakage into the fuel-lean region is possible only for those hydrccarbons which do not significantly inhibit the $C O$ reaction.

\subsection{Detailed Analysis of Inhibition by Methane and Determination of the Rate Constant for $\mathrm{CH}_{4}+\mathrm{OH}$}

Figure 7 shows the computed concentrations of $\mathrm{CO}, \mathrm{O}_{2}, \mathrm{CH}_{4}, \mathrm{H}, \mathrm{O}, \mathrm{OH}$, and $\mathrm{HO}_{2}$ at a reaction time of $80 \mathrm{~ms}$ as a function of the initial methane concentration. The calculations were for a homogeneous isothermal system based on the detailed mechanism described above. The mixture is similar to that of experiment $\mathcal{A}$. Qualitatively, the behavior is the same as observed in the experiments. The concentrations of $\mathrm{H}, \mathrm{O}$, and $\mathrm{OH}$ clearly show a 
transition in reaction at an initial methane concentration of approximately $450 \mathrm{ppm}$. The critical $\mathrm{CH}_{4}$ level is observed nut to equal the initial $\mathrm{CH}_{4}$ concentration. For very small initial $\mathrm{CH}_{4}$ concentrations, the trends of the model are slightly different than those of the experiment because of the temperature rise associated with the oxidation of $C O$.

Experimental results of the $\log$ normalized $\mathrm{CO}$ and $\mathrm{CH}_{4}$ concentrations, which illustrate this explosive characteristic as a function of time, are shown in Fig. 8. The existence of three regimes are seen in the concentration profiles; an induction period, a slow-steady reaction, and finally, an fast-explosive reaction. The critical concentrations of $[\mathrm{CO}]_{\mathrm{e}}$ and $\left[\mathrm{CH}_{4}\right]_{\mathrm{e}}$ are defined as indicated in the figure. Interestingly, this same process moderated by transport phenomena occurs both in premixed and diffusion hydrocarbon/air flames.

The effect of the chosen observation reaction time on the inhibition limit was also studied numerically. After about $70 \mathrm{~m} / \mathrm{s}$, this limit moves to higher initial methane concentrations at a steady and linear rate as a result of steady-state conditions prevailing for the radicals. More importantly, if the inhibition limit is defined as the $\mathrm{CO}$ concentration co-existing with the peak in $\mathrm{HO}_{2}$ and $\mathrm{CH}_{3}$ concentrations, the critical methane level was observed to remain nearly constant, independent of time. To measure the critical $\mathrm{RH}$ level, the reaction time of the experiments need not be known, only that the observation time is during the steady-state period as defined above. By experimentally checking for the independence of the critical $R H$ concentration with respect to time, a method for verifying steady-state conditions among the radicals was obtained.

The sensitivities of the $\mathrm{CO}, \mathrm{CH}_{4}$, and $\mathrm{H}$ concentrations with respect to various elementary reactions were examined as a function of initial $\mathrm{CH}_{4}$ concentration at a reaction time of 80 ms. Qualitatively, the gradient profiles for the $\mathrm{CO}$ and $\mathrm{CH}_{4}$ concentrations show the existence of the same sharp transition previously observed in the radical concentrations. A ranking of the important reactions on the $\mathrm{CO}, \mathrm{CH}_{4}$, and $\mathrm{H}$ concentration profiles, in the neighborhood of the transition point, is in decreasing order

$$
\begin{gathered}
\dot{H}+\mathrm{O}_{2} \rightarrow \dot{\mathrm{OH}}+\ddot{\mathrm{O}} \\
\mathrm{CO}+\dot{\mathrm{O} H} \rightarrow \mathrm{CO}_{2}+\dot{H} \\
\mathrm{C} \mathrm{H}_{4}+\dot{\mathrm{O} H} \rightarrow \dot{\mathrm{C}} \mathrm{H}_{3}+\mathrm{H}_{2} \mathrm{O} \\
\dot{\mathrm{H}}+\mathrm{O}_{2}+\mathrm{M} \rightarrow \mathrm{HO}_{2}+\mathrm{M} \\
\dot{\mathrm{C}} \mathrm{H}_{3}+\dot{\mathrm{H}}+\mathrm{M} \rightarrow \mathrm{CH}_{4}+\mathrm{M} \\
\mathrm{CH}_{3}+\mathrm{HO}_{2} \rightarrow \mathrm{CH}_{3} \dot{\mathrm{O}}+\mathrm{M} \\
\ddot{\mathrm{O}}+\mathrm{H}_{2} \mathrm{O} \rightarrow \dot{\mathrm{O} H}+\dot{\mathrm{O} H} \\
\mathrm{CH}+\dot{H} \rightarrow \dot{\mathrm{C}} \mathrm{H}_{3}+\mathrm{H}_{2} \\
\mathrm{CO}+\ddot{\mathrm{O}}+\mathrm{M} \rightarrow \mathrm{CO}_{2}+\mathrm{M}
\end{gathered}
$$


The importance of secondary reactions involving $\mathrm{CH}_{3}$ results from the relatively large initial methane concentrations required to totally inhibit the $C O$ reaction. The reaction of methyl radical with $\mathrm{O}_{2}$ to form the methoxy radical and $O$-atom is quite slow as is the thermal decomposition reaction, thus enabling radical-radical reactions to compete favorably. The important methyl consuming reactions are predicted to be recombination with $\mathrm{H}$-atoms and reaction with $\mathrm{HO}_{2}$. Note that the reaction steps which normally and sequentially occur after the oxidation of $\mathrm{CH}_{3}$ radicals (e.g., those involving $\mathrm{CH}_{2} \mathrm{O}, \mathrm{HCO}$, etc.) are not important in these systems.

For systems in which steady-state conditions hold for the radical pool, a steady-state treatment was applied to interpret the observed inhibition limit. A steady-state analysis similar to that for obtaining the second explosion limit of the $\mathrm{H}_{2} / \mathrm{O}_{2}$ system ${ }^{27}$ can be applied to the $\mathrm{CO} / \mathrm{H}_{2} \mathrm{O} / \mathrm{O}_{2}$ system to obtain its explosion limit. Here, the controlling reactions at atmospheric pressure are those listed earlier, reactions $11,15,19,48$, and 50 . If the time rate of change of the concentrations of chain carriers $H, O$, and $O H$ are written and then rearranged to eliminate the $H$ and $O$ concentrations, one obtains arı equation for the sum rate of change of these radicals in terms of the $\mathrm{OH}$ concentration. From this latter equation, the condition for a positive growth of the radical pool results as

$$
[M]_{e}=\left(\frac{Z^{2}}{4}+\frac{2 k_{15} k_{19}\left[H_{2} O\right]}{k_{48} k_{S(1)}[C O] K^{2}}\right)^{0.5}-\frac{Z}{2}
$$

where $[M]_{\mathrm{e}}$ is the explosion pressure, $\mathrm{Z}=\left(\mathrm{k}_{19}\left[\mathrm{H}_{2} \mathrm{O}\right] / \mathrm{k}_{50}[\mathrm{CO}] E\right), E=X\left(\mathrm{~N}_{2}\right)+X\left(\mathrm{O}_{2}\right)+$ $16 X\left(\mathrm{H}_{2} \mathrm{O}\right)+1.9 X(\mathrm{CO})$ and $X$ represents a species mole fraction. If the experimental conditions from Ref. 15 are substituted (i.e., $\mathrm{X}\left(\mathrm{H}_{2} \mathrm{O}\right)=0.014, \mathrm{X}(\mathrm{CO})=0.0093, \mathrm{X}\left(\mathrm{O}_{2}\right)=0.0046$, $P=1 \mathrm{~atm})$, a temperature of $965 \mathrm{~K}$ is obtained which is in good agreement with experiment $(950-960 K)$.

By assuming steady-state conditions for $\mathrm{H}, \mathrm{O}, \mathrm{OH}, \mathrm{HO}_{2}$, and $\mathrm{CH}_{3}$, an equation for the critical methane concentration was derived based on a simplified mechanism consisting of the reactions listed above:

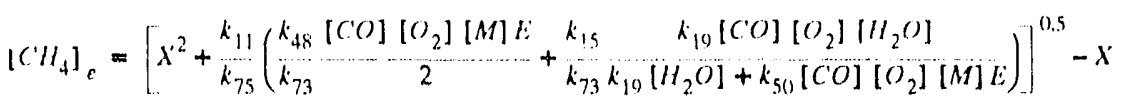

where

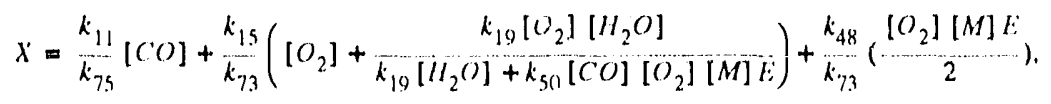

Knowing the concentrations at the critical condition, this equation was solved for the $\mathrm{CH}_{4}$ $+\mathrm{OH}$ rate constant. Experimental results of $T_{\mathrm{e}},[\mathrm{CO}]_{\mathrm{e}},\left[\mathrm{H}_{2} \mathrm{O}\right]_{\mathrm{e}},\left[\mathrm{O}_{2}\right]_{\mathrm{e}}$, and $\left[\mathrm{CH}_{4}\right]_{\mathrm{e}}$ are presented in Table II. The table also reports the presence of any secondary hydrocarbon intermediates measured at the inhibition limit. All the data were obtained with a $\mathrm{CO} / \mathrm{H}_{2} \mathrm{O} / \mathrm{O}_{2}$ mixture similar to mixture. $x$. The experimental data show the presence of very small concentrations of ethylene and ethane at the critical condition. The rate constant assumed for $\mathrm{CH}_{4}+\mathrm{H}$ was from Clark and Dove. ${ }^{28}$ The results of $k(1 / 4+\mathrm{OH}$ are: $\log k=12.21,12.25$, 12.27 and $12.38 \mathrm{~cm}^{3} / \mathrm{mol}-\mathrm{s}$ at $T=1026,1028,1030,1140 \mathrm{~K}$, respectively. Comparison with the TST calculations of Cohen ${ }^{29}$ and other mea. ired values ${ }^{30}$ are in good agreement. 
A similar analysis was conducted for propene addition. Like methane, the data from the propene experiments showed the presence of only small concentrations of secondary hydrocarbon products. As a result of several possible product channels, the present analysis evaluated the rate constant for the reaction,

$$
\mathrm{C}_{3} \mathrm{H}_{6}+\mathrm{OH} \rightarrow \text { products. }
$$

Furthermore, steady-state conditions were assumed only for the $\mathrm{O}, \mathrm{H}$, and $\mathrm{OH}$ radicals. The regeneration of these raticals by further reaction of the products from the primary propene - radical reactions was assumed minimal. The value of the rate constant for the $\mathrm{C}_{3} \mathrm{H}_{6}+\mathrm{H}$ reaction was taken from Westbrook and Pitz $\left(k=5 \times 10^{12} \exp (-1500 / R T) \mathrm{cm}^{3} /\right.$ mol-s). The resulting rate constant for the $\mathrm{C}_{3} \mathrm{H}_{6}+\mathrm{OH}$ reaction at $1020 \mathrm{~K}$ was $8 \times 10^{12} \mathrm{~cm}^{3} /$ mol.s. The value is approximately equal to other room temperature data ${ }^{30}$ and indicates a nearly temperature independent rate as suggested by Warnatz. ${ }^{30}$

\subsection{Summary}

This paper has presented results on the interaction chemistry of the carbon monoxide - hydrogen - oxygen reaction with small quantities of various hydrocarbons. The inhibiting action of the hydrocarbon on the second explosion limit was found to yield rate data on hydrogen - atom abstraction reactions by hydroxyl radical. For methane, the obtained rate constant was found to be in good agreement with literature results. The inhibition experiments also showed that $O$ - atom reactions with the ethane, ethylene, and acetylene dominated over the corresponding $H$ and $O H$ radical reactions. The addition of very small quantities of hydrocarbon to the $C O$ reaction appears to be a feasible method for studying the reactions of $\mathrm{OH}, \mathrm{O}$ and $\mathrm{H}$ with the added hydrocarbon. Modeling of these experiments may be performed to test existing rate data or to evaluate rate data for these reactions.

\section{Acknowledgements}

The authors acknowledge support from the U.S. Department of Energy, Division of Chemical Sciences, Office of Basic Energy Sciences, under Grant No. DE-FG0289ER 13503. 


\subsection{References}

1. see for example, Baldwin, R.R, Jackson, D., Walker, R.W., and Webster, S.J., Tenth Symposium (International) on Combustion, p. 423, The Combustion Institute, Pittsburgh, PA, 1965.

2. Baldwin, R.R., and Cowe, D.W.: Trans. Faraday Soc. 58, 1766 (1963).

3. Baldwin, R.R., and Simmons, R.F.: Trans. Faraday Soc. 51, 680 (1955).

4. Baldwin, R.R., and Simmons, R.F.: Trans. Faraday Soc. 53, 964 (1957).

5. Baldwin, R.R.: Trans. Faraday Soc., 60, 527 (1964).

6. Baldwin, R.R., and Walker, R.W.: Trans. Faraday Soc, 60, 1236 (1964).

7. Baldwin, R.R., Corney, N.S., and Walker, R.W.: Trans. Faraday Soc. 56, 802 (1960)

8. Baldwin, R.R., Booth, D., and Walker, R.W.: Trans. Faraday Soc. 58, 60 (1962).

9. Baldwin, R.R., and Walker, R.W.: Trans. Färaday Soc, 60, 1760 (1964).

10. Baldwin, R.R., Hopkins, D.E., and Walker, R.W.:Trans, Faraday Soc. 66, 189 (1970).

11. Baldwin, R.R., Everett, C.J., Hopkins, D.E., and Walker, R.W.: Advan. Chem. Ser., No 76, p. 124 (1968).

12. Baldwin, R.R., Norris, A.C., and Walker, R.W.: Eleventh Symposium (International) on Combustion, p. 889. The Combustion Institute, Pittsburgh, PA, (1967).

13. Brabbs, T.A. and Brokaw, R.S.: NASA Technical Report Memorandum 82954 (1982).

14. Skinner, G.B., and Ringrose, G.H.: J. Chem. Phys. 43, 4129 (1965).

15. Yetter, R.A., Dryer, F.L., and Rabitz, H.: Combust. Sci. Technol., 79, 97(1991).

16. Roesler, J.F., Yetter, R.A., and Dryer, F.L.: Combust. Sci. Technol., to be submitted (1991).

17. Kee, R.J., Miller, J.A., and Jefferson, T.H.: Sandia National Laboratories, Report SAND80-8003, Livermore, CA (1982).

18.Kramer, M.A., Rabitz, H., and Kee, R.J.: Sandia National Laboratories, Report SAND82-9231, Livermore, CA (1982).

19. Hindmarsh, A.C.: in ACM Sigum Newsletter 15, 4 (1980).

20. Yetter, R.A., Ph.D. Thesis, Dept. of Mechanical and Aerospace Engineering, Princeton University, Princeton, NJ (1985).

21. Dryer, F.L., Ph.D. Thesis, Dept. of Mechanical and Aerospace Engineering, Princeton University, Princeton, NJ (1972).

22. Hautman, D., Ph.D. Thesis, Dept. of Mechanical and Aerospace Engineering, Princeton University, Princeton, NJ (1980).

23. Yetter, R.A., Dryer, F.L., and Rabitz, H.: Combust. Sci. Technol. 79, 129 (1991).

24. Euchner, J.A., M.S.E. Thesis, Dept. of Mechanical and Aerospace Engineering, Princeton University, Princeton, NJ (1980). 
25. Proscia, W.M., M.S.E. Thesis, Dept. of Mechanical and Aerospace Engineering, Princeton University, Princeton, NJ (1983).

26. Venkat, C., M.S.E. Thesis, Dept. of Chemical Engineering, Princeton University, Princeton, NJ (1981).

27. Lewis, B., and von-Elbe, G., Combustion, Flames, and Explosions of Gases, Academic Press, NY, 1961.

28. Clark, T.C. and Dove, J.E.: Canad. J. Chem. 51, 2147 (1973).

29. Cohen, N.: Iit. J. Cisem. Kinet. 14, 1339 (1982).

30. Warnatz, J.:in Combustion Chemistry, W. Gardiner, Jr., ed., Springer-Verlag, NY, NY, 1985. 


\subsection{Tables}

TABLE I. Rate Constants of Specific Radical Reactions."

\begin{tabular}{|c|c|c|c|}
\hline Peaction & $1000 K^{\prime}$ & $1200 K^{\prime}$ & $2000 K$ \\
\hline $\mathrm{C}_{3} \mathrm{H}_{8}+\mathrm{OH}$ & $1.1 \times 10^{13}$ & $1.5 \times 10^{13}$ & $3.6 \times 10^{13}$ \\
\hline $\mathrm{C}_{2} \mathrm{H}_{6}+\mathrm{OH}$ & $4.7 \times 10^{12}$ & $6.6 \times 10^{12}$ & $1.5 \times 10^{13}$ \\
\hline $\mathrm{CH}_{4}+\mathrm{OHI}$ & $1.1 \times 10^{12}$ & $2.0 \times 10^{12}$ & $9.5 \times 10^{12}$ \\
\hline $\mathrm{H}_{2}+\mathrm{OH}$ & $1.3 \times 10^{12}$ & $2.3 \times 10^{12}$ & $8.7 \times 10^{12}$ \\
\hline $\mathrm{CO}+\mathrm{OH}$ & $1.7 \times 10^{11}$ & $2.0 \times 10^{11}$ & $4.1 \times 10^{11}$ \\
\hline $\mathrm{C}_{3} H_{8}+H$ & $1.9 \times 10^{12}$ & $6.4 \times 10^{12}$ & $6.5 \times 10^{13}$ \\
\hline $\mathrm{C}_{2} H_{6}+H$ & $1.3 \times 10^{12}$ & $3.8 \times 10^{12}$ & $5.4 \times 10^{13}$ \\
\hline $\mathrm{CH}_{4}+\mathrm{HI}$ & $2.7 \times 10^{11}$ & $9.9 \times 10^{11}$ & $2.0 \times 10^{13}$ \\
\hline $\mathrm{O}_{2}+\mathrm{HI}$ & $4.9 \times 10^{10}$ & $1.9 \times 10^{11}$ & $3.0 \times 10^{12}$ \\
\hline$(\mathrm{M}+) \mathrm{O}_{2}+H$ & $4.5 \times 10^{10}$ & $2.9 \times 10^{10}$ & $8.5 \times 10^{9}$ \\
\hline$C_{3} H_{8}+O$ & $2.2 \times 10^{12}$ & $4.1 \times 10^{12}$ & $1.9 \times 10^{13}$ \\
\hline $\mathrm{C}_{2} \mathrm{H}_{6}+\mathrm{O}$ & $1.9 \times 10^{12}$ & $3.9 \times 10^{12}$ & $1.8 \times 10^{13}$ \\
\hline $\mathrm{CH}_{4}+\mathrm{O}$ & $4.3 \times 10^{11}$ & $1.2 \times 10^{12}$ & $1.1 \times 10^{13}$ \\
\hline $\mathrm{H}_{2}+\mathrm{O}$ & $2.2 \times 10^{11}$ & $6.1 \times 10^{11}$ & $6.9 \times 10^{12}$ \\
\hline $\mathrm{H}_{2} \mathrm{O}+\mathrm{O}$ & $6.7 \times 10^{9}$ & $3.5 \times 10^{10}$ & $1.2 \times 10^{12}$ \\
\hline
\end{tabular}

TABLE II. Critical composition data at the steady-state limit."

\begin{tabular}{|c|c|c|c|c|c|c|c|c|c|c|c|}
\hline $\mathbf{R} H$ & $\mathrm{CO}$ & $\mathrm{O}_{2}$ & $\mathrm{H}_{2} \mathrm{O}$ & $\mathrm{CO}_{2}$ & $\mathrm{CH}_{4}$ & $\mathrm{C}_{2} \mathrm{H}_{4}$ & $\mathrm{C}_{2} H_{6}$ & $\mathrm{C}_{\mathbf{Y}} \mathrm{H}_{4}$ & $C_{3} H_{6}$ & $C_{4} I_{8}$ & $T$ \\
\hline $\mathrm{ClI}_{4}$ & 0.927 & 0.932 & 0.812 & 0.097 & 367 & 10.5 & 8.5 & $*$ & * & * & 1026 \\
\hline $\mathrm{CH}_{4}$ & 0.932 & 0.932 & 0.812 & 0.063 & 373 & 10.5 & 9.2 & $*$ & * & * & 1026 \\
\hline $\mathrm{CH}_{4}$ & 0.931 & 0.932 & 0.812 & 0.059 & 370 & 11.9 & 8.9 & * & $*$ & * & 1026 \\
\hline $\mathrm{CH}_{4}$ & 0.9 & 0.86 & 0.74 & * & 302 & * & $*$ & * & $*$ & * & 1030 \\
\hline $\mathrm{CH}_{4}$ & 0.91 & 0.875 & 0.812 & * & 328 & * & $*$ & * & * & * & 1028 \\
\hline $\mathrm{CH}_{4}$ & 0.905 & 0.875 & 0.790 & * & 302 & $*$ & * & * & * & * & 1028 \\
\hline$C_{3} H_{6}$ & 0.959 & 0.982 & 0.812 & $*$ & * & 6.1 & 1.1 & 0.27 & 109 & 2.1 & 1020 \\
\hline$C_{3} H_{6}$ & 0.968 & 0.973 & 0.812 & 0.004 & * & 6.2 & 1.1 & 0.28 & 109 & 2 & 1020 \\
\hline$C_{3} H_{6}$ & 0.970 & 0.973 & 0.812 & 0.004 & * & 6.6 & 1.1 & 0.25 & 108 & 2.2 & 1020 \\
\hline
\end{tabular}




\subsection{Figure Captions}

FIGURE 1. Schematic of premixed (a) and diffusion (b) flames and the location within these flames of the type of kinetics studied here.

FIGURE 2. Sensitivity gradients of the methane concentration with respect to various reaction rate constants. Initial conditions: $T=1150 \mathrm{~K}, P=1 \mathrm{~atm}, \mathrm{X}\left(\mathrm{C} H_{4}\right)=0.01$, and $\mathrm{X}\left(\mathrm{O}_{2}\right)=0.20$. The balance of the mixture is nitrogen. Note the scale change occurring at unity. (a) positive gradients (b) negative gradients. The numbers at the right of the figure denote the reactions in decreasing order of importance at $80 \%$ consumption. Reactions are:

\begin{tabular}{|c|c|c|c|}
\hline $11, \mathrm{CO}+\mathrm{OH} \cdot \mathrm{CO}_{2}+\mathrm{H}$ & $15, \mathrm{H}+\mathrm{O}_{2}-\mathrm{OH}+\mathrm{O}$ & $19 . \mathrm{O}+\mathrm{H}_{2} \mathrm{O}-\mathrm{OH}+\mathrm{OH}$ & $\left.25,11 \mathrm{O})_{2}+\mathrm{O}-\mathrm{O}_{2}+\mathrm{O}\right) \mathrm{H}$ \\
\hline 27. $\mathrm{H}+\mathrm{HO}_{2}-\mathrm{OH}+\mathrm{OH}$ & $31, \mathrm{HO}_{2}+\mathrm{OH}-\mathrm{H}_{2} \mathrm{O}+\mathrm{O}_{2}$ & $34 . \mathrm{HO}_{2}+\mathrm{HO}_{2} \cdot \mathrm{H}_{2} \mathrm{O}_{2}+\mathrm{O}_{2}$ & 43. $\mathrm{H}_{2} \mathrm{O}_{2}+\mathrm{M} \cdot \mathrm{OH}+\mathrm{OH}+\mathrm{M}$ \\
\hline $48, \mathrm{H}+\mathrm{O}_{2}+\mathrm{M} \cdot \mathrm{HO}_{2}+\mathrm{M}$ & $\left.61, \mathrm{CH}_{2} \mathrm{O}+\mathrm{OH} \cdot \mathrm{HCO} \mathrm{O}+\mathrm{H}_{2} \mathrm{O}\right)$ & $65 . \mathrm{CH}_{2} \mathrm{O}+\mathrm{O}-\mathrm{OH}(\mathrm{O})+\mathrm{OH}$ & 67. $\left(\mathrm{H}_{2} \mathrm{O}+\mathrm{HO}_{2}-\mathrm{HCO}+\mathrm{H}_{2} \mathrm{O}_{2}\right.$ \\
\hline $71, \mathrm{CH}_{4}+\mathrm{O}_{2}-\mathrm{CH}_{3}+\mathrm{HO}_{2}$ & 72. $\mathrm{CH}_{3}+\mathrm{HOO}_{2}-\left(\mathrm{CH}_{4}+\mathrm{O}_{2}\right.$ & 73. $\left(H_{4}+H \cdot C \cdot H_{3}+H_{2}\right.$ & $\left.75, \mathrm{CH}_{4}+\mathrm{O}\right) \mathrm{H} \cdot \mathrm{C} \mathrm{CH}_{3}+\mathrm{H}_{2} \mathrm{O}$ \\
\hline $77 \cdot\left(\mathrm{H}_{4}+\mathrm{O} \cdot \mathrm{CH}_{3}+\mathrm{OH}\right.$ & 79, $\mathrm{CH}_{4}+\mathrm{HO}_{2}-\mathrm{CH}_{3}+\mathrm{H}_{2} \mathrm{O}_{2}$ & $81, \mathrm{CH}_{3}+\mathrm{O}_{2}-\left(\mathrm{CH}_{3} \mathrm{O}+\mathrm{O}\right)$ & $83, \mathrm{CH}_{3}+\mathrm{CH}_{3} \cdot \mathrm{C}_{2} \mathrm{H}_{6}$ \\
\hline 95, $\mathrm{CH}_{3}+\mathrm{CH}_{2} \mathrm{O}-\mathrm{CH}_{4}+\mathrm{HCO}$ & $99, \mathrm{CH}_{3}+\mathrm{HO}_{2}-\mathrm{CH}_{3} \mathrm{O}+\mathrm{OH}$ & 103. $\mathrm{CH}_{3} \mathrm{O}+\mathrm{M} \cdot \mathrm{CH}_{2} \mathrm{O}+\mathrm{H}+\mathrm{M}$ & 105. $\mathrm{CH}_{3} \mathrm{O}+\mathrm{O}_{2}-\mathrm{CH}_{2} \mathrm{O}+\mathrm{HO}_{2}$ \\
\hline 11H, $\mathrm{C}_{2} \mathrm{H}_{6}+\mathrm{CH}_{3}-\mathrm{C}_{2} \mathrm{H}_{5}+\mathrm{CH}_{4}$ & $117, \mathrm{CH}_{3} \mathrm{O}+\mathrm{H} \cdot \mathrm{CH}_{2} \mathrm{O}+\mathrm{H}_{2}$ & & \\
\hline
\end{tabular}

FIGURE 3. Sensitivity gradients of the methane concentration with respect to various reaction rate constants. Initial col ditions: $T=1150 \mathrm{~K}, P=1 \mathrm{~atm}, X(C O)=0.01, X\left(H_{2} O\right)=0.03, X\left(O_{2}\right)=0.20$, and $\mathrm{X}\left(\mathrm{CH}_{4}\right)=0.0005$. The balance of the mixture is nitrogen. See caption of Fig. 2 for reaction numbers.

FIGURE 4. $\mathrm{CO}$ concentration profiles for three uninhibited reactions. STAR: Mixture $A ; \mathrm{X}(C O)=$ $0.0093, X\left(O_{2}\right)=0.0091, X\left(H_{2} O\right)=0.0079, T=1024 K^{\prime}, P=1$ atm. DIAMOND: Mixture $B ; X(C O)=$ $0.0097, \mathrm{X}\left(\mathrm{O}_{2}\right)=0.0031, \mathrm{X}\left(\mathrm{H}_{2} \mathrm{O}\right)=0.0081, \mathrm{~T}=1026 \mathrm{~K}, \mathrm{P}=1 \mathrm{~atm}$. SQUARE: Mixture $C ; \mathrm{X}(\mathrm{CO})=0.0096$ $\mathrm{X}\left(\mathrm{O}_{2}\right)=0.0094, X\left(\mathrm{H}_{2} \mathrm{O}\right)=0.0027, T=1023 \kappa, P=1 \mathrm{~atm}$.

FIGURE 5. Variation in $\mathrm{CO}$ and $\mathrm{O}_{2}$ concentrations at $84 \mathrm{~ms}$ as a function of initial hydrocarbon concentration for mixture $\lambda_{4} C_{3} H_{8}$ (DIAMOND); $C_{4} H_{4}$ (SQUARE), $C_{2} H_{6}$ (PENTAGON); $C_{2} I_{4}$ (HEXAGON); $\mathrm{C}_{2} \mathrm{H}_{2}$ (OCTAGON). The dashed lines indicate the initial $C O$ and $O_{2}$ concentrations.

FIGURE 6. Variation in $\mathrm{CO}$ concentrations at $84 \mathrm{~ms}$ as a function of initial hydrocarbon concentration for mixtures $\mathcal{B}$ and $C_{\text {. }} C_{3} I_{6}$ (STAR) $C_{3} H_{8}$ (DIAMOND); $C H_{4}$ (SQUARE), $C_{2} I_{6}$ PENTAGON); $\mathrm{C}_{2} H_{4}$ (HEXAGON); $\mathrm{C}_{2} H_{2}$ (OCTAGON). The dashed lines indicate the initial $\mathrm{CO}^{\prime}$ concentrations.

FIGURE 7. Numerical calculations of the variation In $\mathrm{CO}$ (LONG DASH-SHORT DASH), $\mathrm{O}_{2}$ (LONG DASH-DOT), $\mathrm{CH}_{4}$ (SMALL DASH-DOT), $I$ (SMALL DASH), $O$ (SOLID), OH (DOT), and $\mathrm{HO}_{2}$ (LONG DASH) concentrations at a reaction time of $80 \mathrm{~ms}$ as a function of initial methane concentration. The $\mathrm{CO} / \mathrm{H}_{2} \mathrm{O} / \mathrm{O}_{2}$ mixture was $\mathrm{X}(\mathrm{CO})=0.01, \mathrm{X}\left(\mathrm{H}_{2} \mathrm{O}\right)=0.01$, and $\mathrm{X}\left(\mathrm{O}_{2}\right)=0.01$ and was reacted at $1025 K$ and $1 \mathrm{arm}$.

FIGURE 8. Experimental results of the log normalized $\mathrm{CO}$ (DIAMOND $\times$ 10) and $\mathrm{CH}_{4}$ (SQUARE) concentrations vs. reaction time. The separation between the slow-steady reaction and the fastexplosive reaction is indicated by the open symbols, which are the critical $C O$ and $\mathrm{CH}_{4}$ concentrations. The initlal conditions were: $\mathrm{X}(\mathrm{CO})=0.013, \mathrm{X}\left(\mathrm{O}_{2}\right)=0.0119, \mathrm{X}\left(\mathrm{H}_{2} \mathrm{O}\right)=0.0074, \mathrm{X}\left(\mathrm{CH}_{4}\right)=0.000603, \mathrm{~T}=$ $1021 \mathrm{~K}, P=1 \mathrm{~atm}$. 

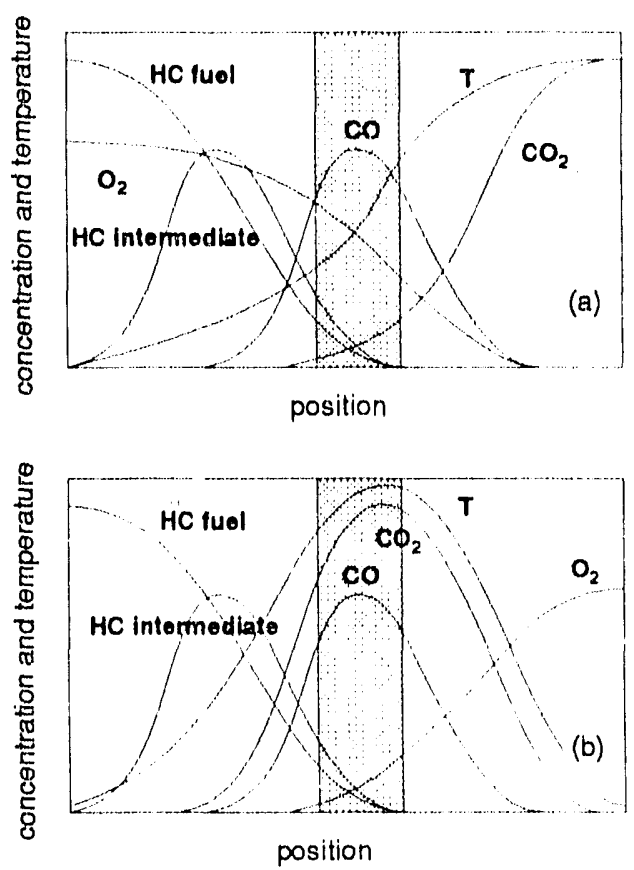

Fig. 1 


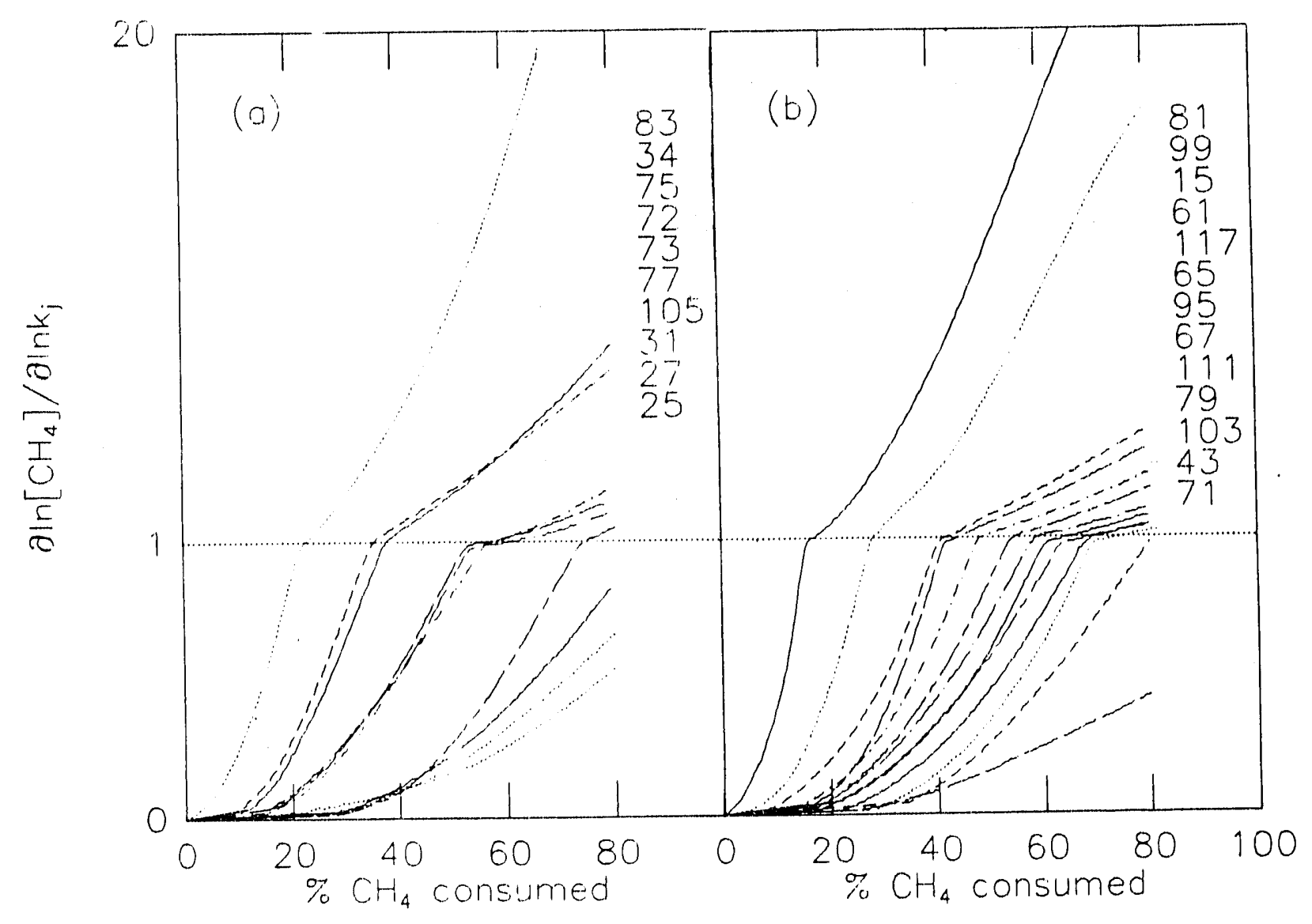

Fig. 2 


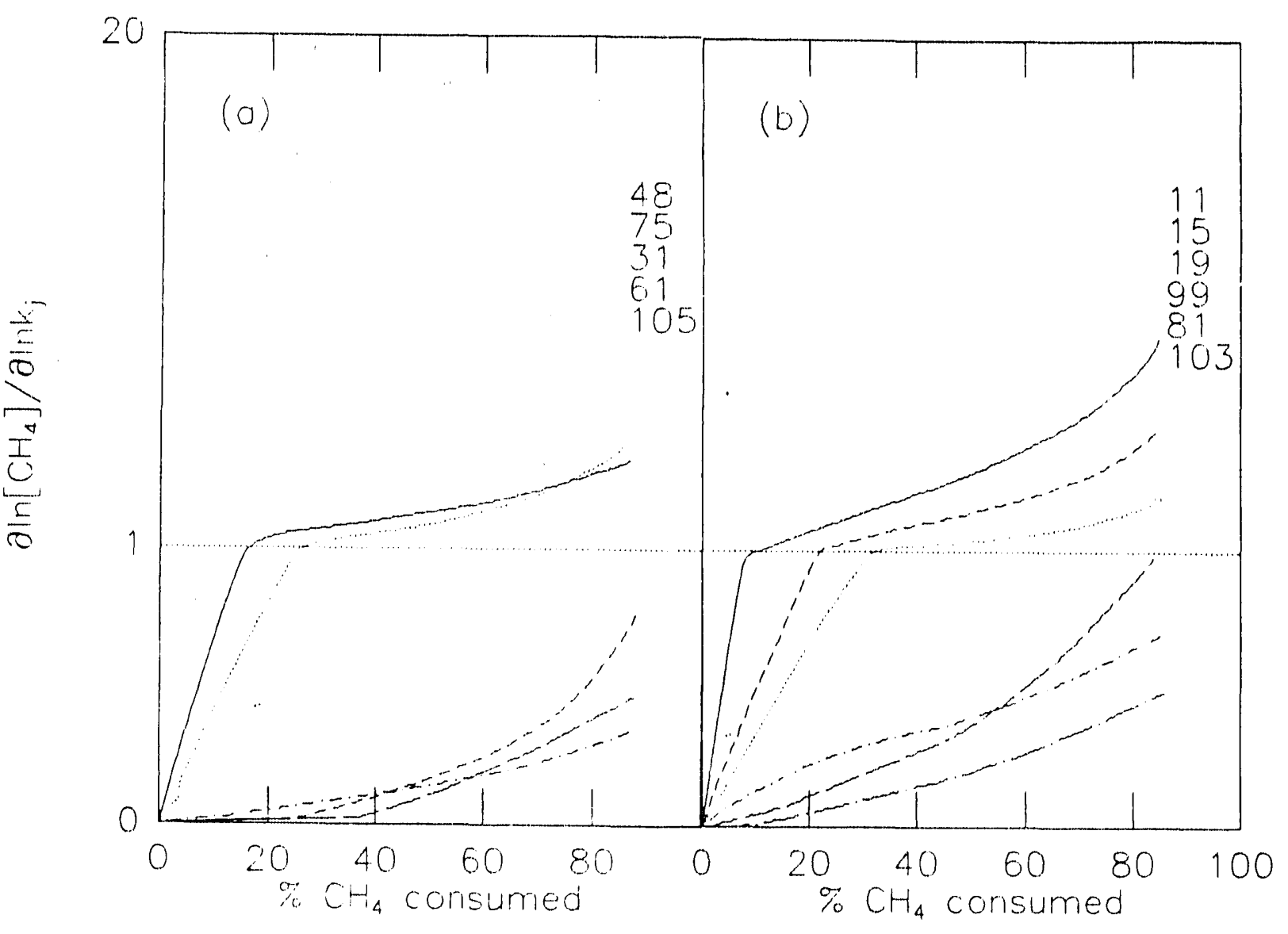

Fia. 3 


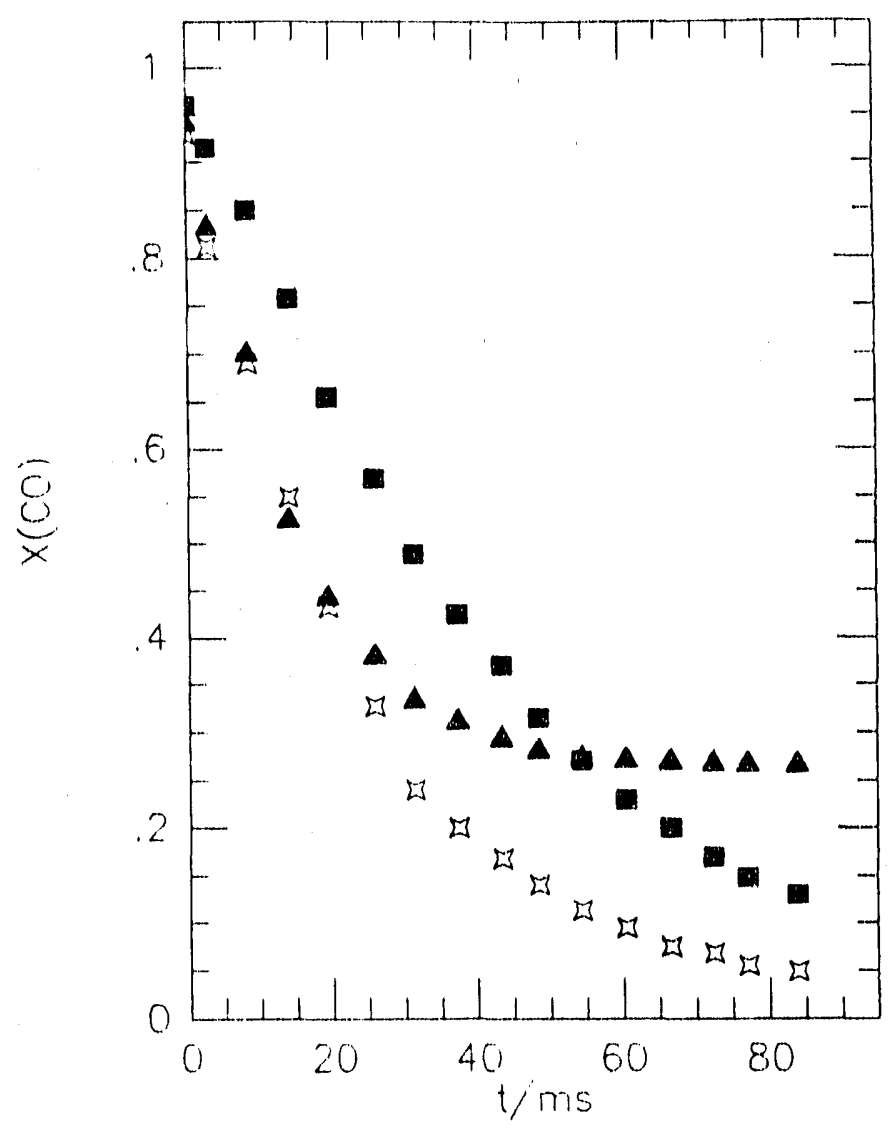

Fig. 4 


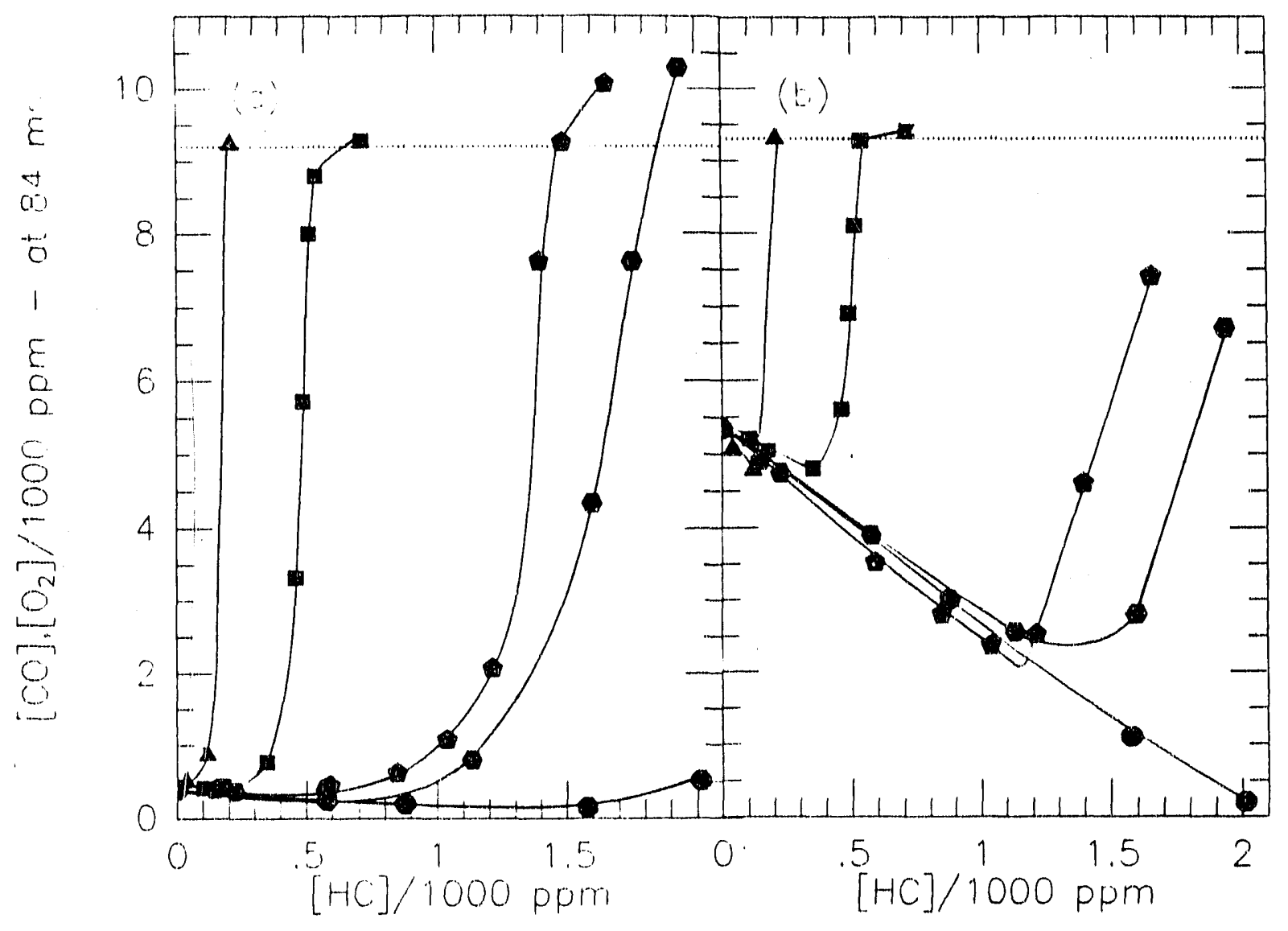

Fig. 5 


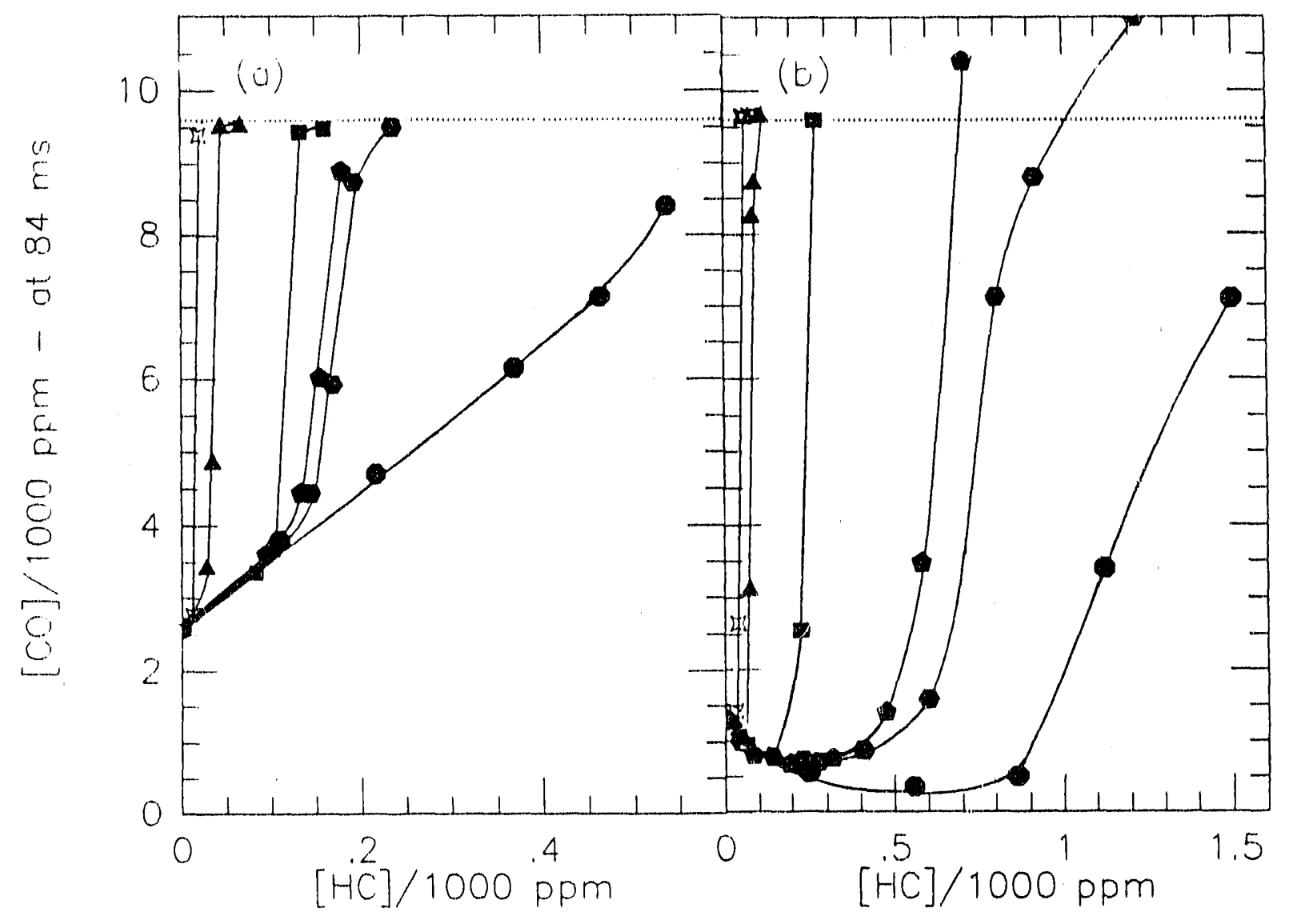

Fig. 6 


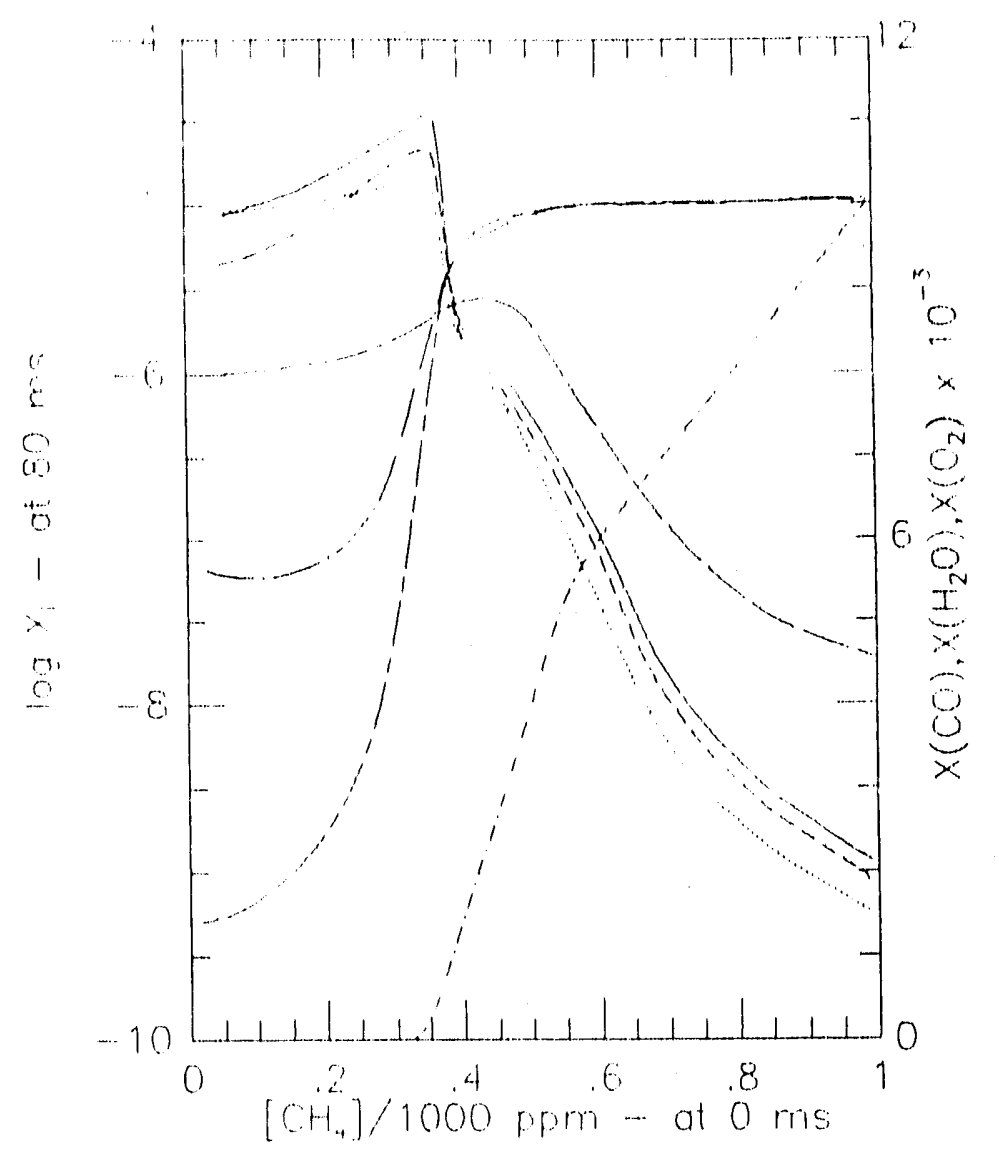

Fig. 7 


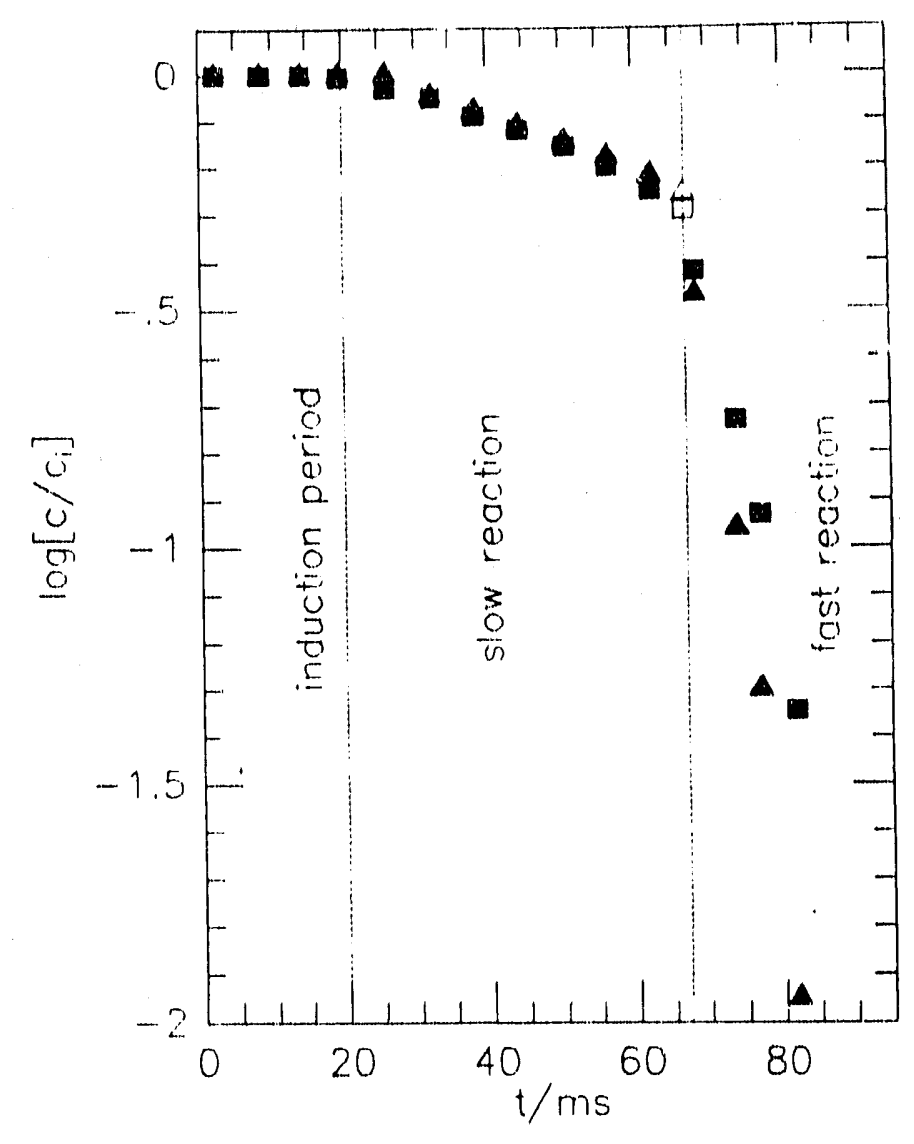

Fig. 8 

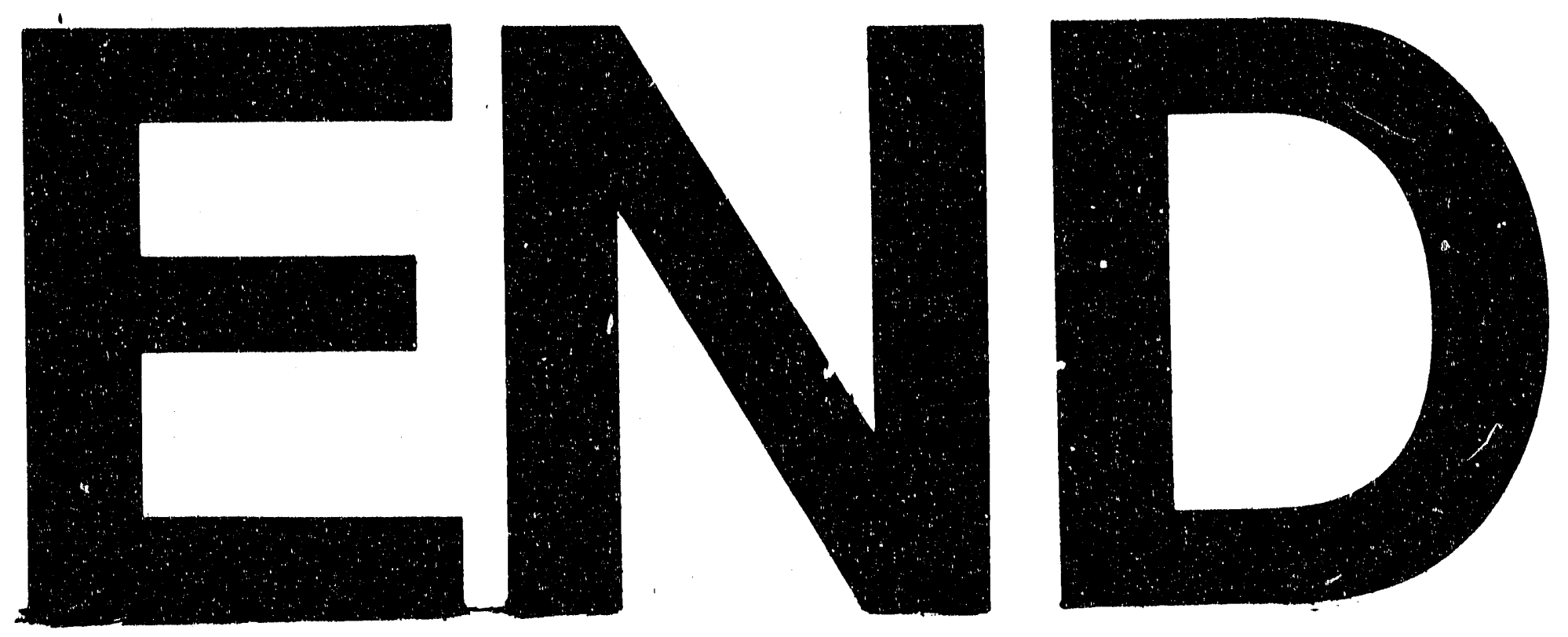

(a)
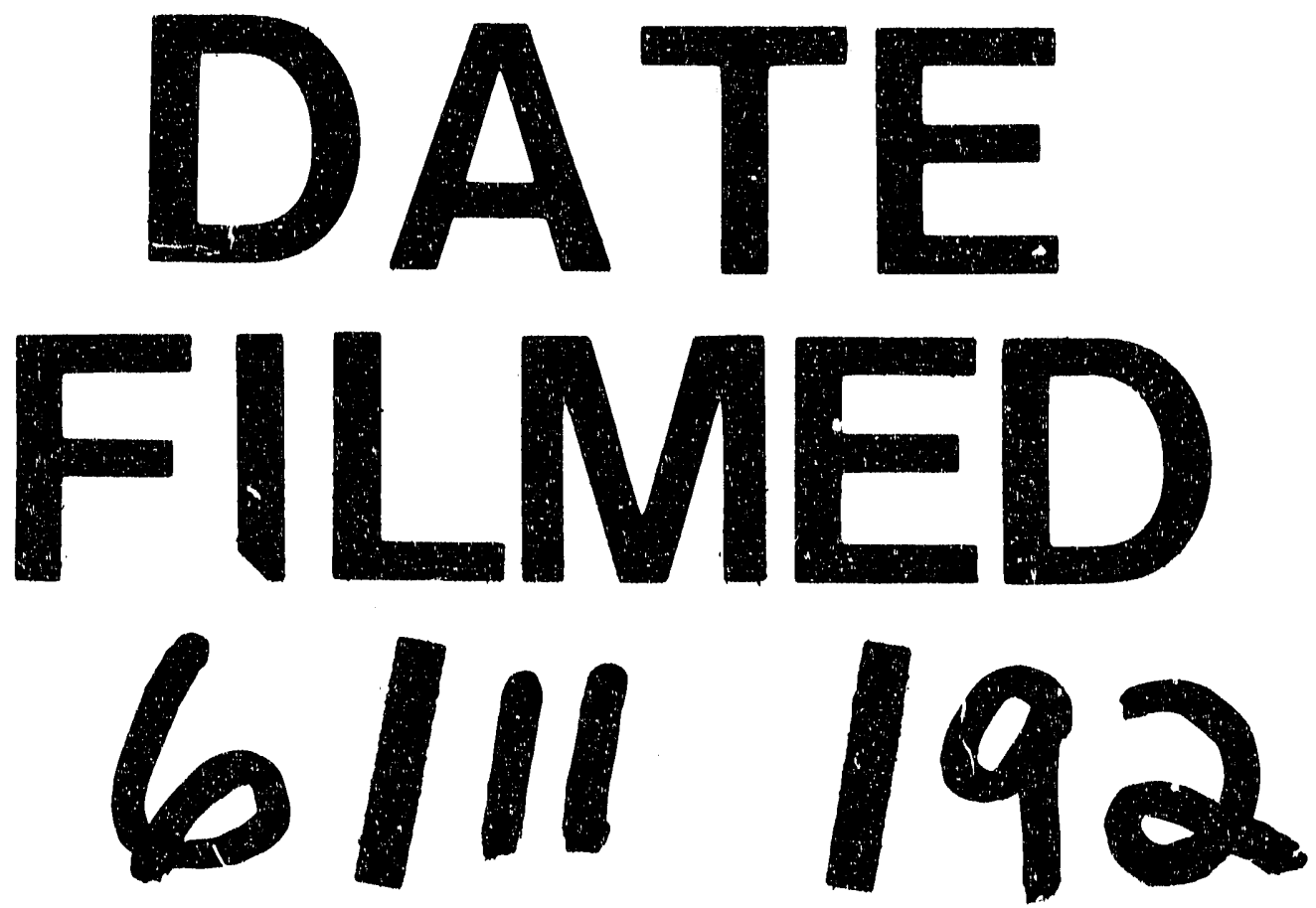


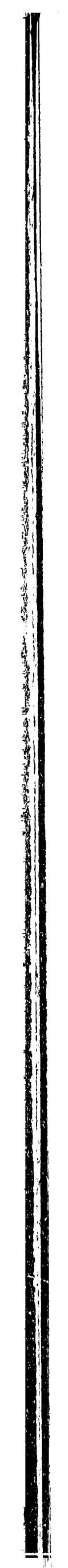

